Working Paper No. 536, 2000

Strategic Investments in the Pulp and Paper Industry: A Count Data Regression Analysis

by Mats A. Bergman and Per Johansson

IUI, The Research Institute of Industrial Economics

P.O. Box 5501

SE-114 85 Stockholm

Sweden 


\title{
Strategic Investments in the Pulp and Paper Industry: A Count Data Regression Analysis*
}

\author{
Mats A. Bergman ${ }^{\dagger}$ and Per Johansson ${ }^{\ddagger}$
}

September 25, 2000

\begin{abstract}
This paper analyses the effects of price and market size variables on the investment propensities in the pulp and paper industry. A panel of 15 European countries in the time period $1984-1997$ is used in the regression analysis. We find the wages, the $U S / E C U$ exchange rate, the price of paper and the installed production capacity to be the main determinants of strategic investments in this industry. Our measure of market size have no - or only very small - effects.

Keywords: Lumpy investments; Prices; Market size; Agglomeration; Distance; Investment determinants.

JEL: L11, L73, E22, D24
\end{abstract}

\section{Introduction}

Investments in the pulp and paper industry are predominantly large and "strategic". This paper explores the determinants of such investments with a panel of European countries.

\footnotetext{
*We thank Kurt Brännäs, Runar Brännlund and seminar participants at the The Research Institute of Industrial Economics.

${ }^{\dagger}$ Swedish Competition Authority, SE-103 85 Stockholm, Sweden and the Research Institute of Industrial Economics, Box 5501, SE-114 85 Stockholm, Sweden.

${ }^{\ddagger}$ IFAU - Office of Labour Market Policy Evaluation, SE-751 20 Uppsala, Sweden and Department of Economics, Umeå University SE-901 87 Umeå, Sweden
} 
The pulp and paper industry has undergone important structural changes in recent decades. The degree of vertical integration between pulp and paper production has increased, as has the average production scale. New technologies and increasing environmental concerns have made recycled paper a more important source of raw materials which, in turn, has created a shift in the industry's centre of gravity from forest-rich regions to densely populated areas. ${ }^{1}$ New production technologies and decreased costs of transportation have increased competition between paper based on northern coniferous species and paper based on southern fast-growing, broad-leaved species. This paper addresses the question of which factors have influenced the investment decisions and analyses the effect of price and market size variables on the investment propensities in the pulp and paper industry.

The fundamental assumption that the flow of investments can be modelled as the result of an on-going adjustment towards an optimal capital stock constitutes the basis of the "traditional" empirical investment literature is. Typically, convex adjustment costs associated with this process are assumed to prevent instant adjustment. Investment models of this kind predict that a firm will often invest, but rarely will there be marked "spikes" in the investment pattern. There is, however, an element of "lumpiness" - or spikes - in the observed investment behavior of the firms. ${ }^{2}$ An empirical approach is to analyse the investment decision, using, e.g., discrete choice regression models.

Discrete choice analyses of investments have been formulated within the industrial organization (IO) literature, which emphasizes the strategic interaction between firms, and within the international and regional economics literature, which focuses on factors such as market size, agglomeration effects, and the geographical distance from the mother company. Neither the IO nor the international and regional economic literature emphasizes adjustment costs, although theoretical models of IO type often include a fixed cost of investment.

In order to address the question of which factors have influenced the investment decisions in the pulp and paper industry, explanatory variables previously used in the "traditional" and "discrete" investment approaches are used. Following that latter tradition, we include only major, strategic investments. An "investment" is defined as the installation of a new processing unit, i.e., a new paper machine

\footnotetext{
${ }^{1}$ This, in fact, reverses the trend that dominated the pulp and paper industry during most of the 20th century - when the industry shifted from population centers, where it was located in the 19th century, to forest regions (Hunter, 1955).

${ }^{2}$ See, e.g., Doms and Dunne (1994), Nilsen and Schiantarelli (1998) and Cooper et al. (1999).
} 
or a new pulp line. These investments are then aggregated to the number of investments in a year, at the national level. Our data constitutes an unbalanced panel of 15 European countries, the EC-15 countries except Greece but including Norway for the years $1984-1996$ (see Table 4.2 for a description of the data). This permits us to remove unobserved country-specific effects.

We find that wages and the installed production capacity have negative and positive significant effects (both economically and statistically), respectively, on the propensity to invest. As concerns other costs, the price of paper might have an economic relevance on the propensity to invest, while the price of electricity, raw materials and interest rates do not seem to be important determinants of strategic investment decisions. The $U S / E C U$ exchange rate has a strong positive estimated effect. Our measures of market size: population, GDP growth and the interaction between these two variables have a strong positive estimated effect, however.

In Section 2, we discuss certain aspects of the pulp and paper industry. Section 3 provides an overview of the related literature while Section 4 describes the data and introduces the econometric model and tests. The results from the estimations are discussed in Section 5. Finally, Section 6 concludes.

\section{The pulp and paper industry}

The pulp and paper industry is an industry where large investments are important and where such investments can relatively easily be defined. In the pulp and paper industry, a typical plant makes some investments most years, replacing or improving part of the machinery. ${ }^{3}$ In most cases, however, investments in new paper machines or new pulp lines constitute more significant undertakings and can correctly be considered as "lumpy". In the late 1980's, the construction cost of a new pulp line was US\$ 400-500 million; the cost of a newsprint paper machine US $\$ 400$ million and the cost of a printing/writing paper machine US\$200-300 million (Zavatta, 1993). ${ }^{4}$

\footnotetext{
${ }^{3}$ For comparison, Cooper et al. (1999) study a sample of large continuously operated (manufacturing sector) processing plants from the U.S. Longitudinal Research Database. They find that at a given time, approximately 20 percent of the plants experience an investment spike, defined as a gross investment rate above 20 percent. This group accounts for nearly 50 percent of all investments. At the same time, 13 percent of the plants have an investment rate of zero or almost zero (less than 0.02).

${ }^{4}$ Some recent newsprint machines have cost up to US\$ 500 million, and some printing/writing paper machines up to US\$ 600 million (Paper International Database). The cost of the largest
} 
In 1997, the turnover of the 50 largest European firms in the industry added up to more than US $\$ 70$ billion. The largest firm, UPM-Kymmene, had a turnover of more than US $\$ 7$ billion and 16 other firms had turnovers exceeding US $\$ 1$ billion. ${ }^{5}$ The merger and acquisition waves of the last two decades have resulted in a number of relatively large firms. However, the industry is still fairly fragmented. In the late 1980s, there were more than 500 paper companies in the EC-6 countries and the UK (Zavatta, 1993). In 1998, the 20 largest European pulp and paper firms accounted for 55 percent of the industry's capacity. ${ }^{6}$

In 1998, the three Nordic countries Finland, Norway and Sweden, with a population of less than 20 million, accounted for two thirds of the pulp production in Western Europe, and 30 percent of the paper and board production (a decrease from 32 percent a decade earlier). There existed a total of 106 pulp mills and 107 paper mills in the Nordic countries (excluding Denmark) in 1998, compared to 107 pulp mills and 905 paper mills within the EC-12 area (including Austria and Switzerland), implying that the average pulp mill capacity was twice as large in the Nordic region and the average paper mill capacity almost four times larger in Scandinavia, compared to the rest of Western Europe. ${ }^{7}$

The shares of operating costs of the Swedish pulp and paper industry and manufacturing industry, respectively, in 1995 are shown in Table 2.1. The two most important differences, however, are not reflected in the table. The first is that the pulp and paper industry is dependent on supplies of wood and/or recycled paper. About half of the raw material for the European paper production is pulp and recycled paper constitutes the bulk of the remaining half. ${ }^{8}$ Second, the capital per employee was more than 3.5 times as high as the average of other

pulp lines and LWC paper machines amounts to similar sums. The 750000 ton Veracel (formerly Veracruz) pulp project in Brazil is estimated at US\$1.6 billion, including, however, the cost of large plantations. (www.veracel.com.br)

CEPI reports the cost of a 250000 tonne newprint line to be 300 million Euro. (www.cepi.org)

${ }^{5}$ Fact \& Figures 1999, Pulp \& Paper International. Turnover of pulp, paper, paperboard and conversion only. The 1998 merger between Enso and Stora resulted in a firm with a turnover of more than US\$ 10 billion, according to the turnover of the firms in 1997.

${ }^{6}$ www.cepi.org. Since the firms specialise in sub-markets, the effective concentration is higher. E.g., five firms account for more than 80 percent of the European newsprint production.

${ }^{7}$ From www.cepi.org. Zavatta (1993) reports 1077 paper mills in the EC-12 area and 119 in the three Nordic countries in the late 1980s, with average production capacities of 34000 tons and 159000 tons, respectively. The corresponding figures for 1998 are 878 and 107 paper mills, with production capacities of 66000 and 252000 tons, respectively.

${ }^{8}$ In addition, non-fibrous materials constitute approximately 15 percent of the material for paper. 
Table 2.1: Factor cost shares in manufacturing and the pulp and paper industry. (Sweden, 1995, percent, excluding capital.)

\begin{tabular}{lrr}
\hline \hline & Manufacturing & Pulp and paper \\
\hline Wages, salaries ${ }^{1}$ & 19.5 & 17.1 \\
Raw materials & 46.7 & 53.2 \\
Electric energy & 1.2 & 4.7 \\
Other operating expenses ${ }^{2}$ & 32.6 & 25 \\
\hline${ }^{1}$ Including social costs & \\
${ }^{2}$ Packaging, fuels, transports, maintenance and repairs, trade \\
goods, costs for purchasing and other expenses. \\
Source: SOS Manufacturing, 1995
\end{tabular}

manufacturing industries in Sweden. ${ }^{9}$

\section{Earlier literature}

In process industries, investments typically can be categorized into three classes. The first is the construction of new plants, or "greenfield" investments. The second is the installation of additional processing units in existing plants. The third is investments in existing processing units, which can be either pure replacement investments, or an investment aimed at increasing the capacity of the unit by bottleneck elimination. The traditional distinction between net investments and replacement investments intersects this classification. A new plant or unit can replace a closed plant or unit within the same firm. A new part for an existing unit can replace a worn-out part and at the same time increase capacity.

The empirical literature on investment can be divided into two broad traditions. The first is the traditional investment literature that models investments as the result of adjustments towards the optimal capital stock. Investments of the above three types are typically aggregated into a single monetary measure. The adjustment costs that extend the investment process over time could either be modelled as implicit or explicit. Examples of the former are the neoclassical investment models; examples of the latter are the q-model and the Euler equation

\footnotetext{
${ }^{9}$ Stocks of fixed assets and national wealth, N10 SM9501, Statistics Sweden. Fixed assets (buildings and machinery) at replacement costs, in 1995, relative to private sector manufacturing employment, Statistical Yearbook, Statistics Sweden.
} 
models with adjustment costs (see Chirinko, 1993, for an overview). Within this tradition, investment is seen as a continuous variable depending on the current and the expected future marginal revenue product of capital and the cost of capital. Various techniques are employed for resolving the problem of unobservable expected values.

The second tradition, where investments are typically seen as discrete events, is really (at least) two quite distinct traditions: the IO tradition and the international/regional economics tradition. These studies focus primarily on "greenfield" investments and investments in additional processing units, although major investments within existing units are also often considered. The investment variable is discrete and equal to one, if an investment has occurred.

Within the IO tradition, the investment decision is modeled as being dependent on such variables as industry concentration, commitment to the investment project and recent incumbent and entrant actions and announcements, as well as measures of demand growth, but not primarily on factor prices. ${ }^{10}$ In particular, there are a number of such studies of the chemical processing industry, including Lieberman (1987 a and b), Gilbert and Lieberman (1987), Campa (1994) and Paraskevopoulos and Pitelis (1995). All these studies use logit regression with firm or industry data. ${ }^{11}$ Christensen and Caves (1997) estimate whether an investment in the pulp and paper industry will occur, given that an investment decision has been announced, using logit regression model. An exit decision is naturally a discrete choice. Deily (1991) uses an ordered logit regression model to explain the firms' choices between the three alternatives of exit, disinvestment by depreciation, and maintenance or expansion of capacity by investments. Kovenock and Philips (1995) estimate exit decisions as well as (discrete) investment decisions in ten industries with limited dependent regression models.

Studies in the international and regional economics tradition focus on such factors as market size, agglomeration effects, and geographical distance from the mother company (e.g., Head et al., 1995, and references therein). Again, factor prices are often not the main focus in empirical studies, despite the great attention paid to factor endowments and factor prices in the theoretical international economics literature. Bartik (1985), Coughlin, Terza and Arromdee (1991) and Friedman, Gerlowski and Silberman (1992) use multinomial logit regression models to analyse where to locate an investment, (e.g., in which US state). Braunerhjelm

\footnotetext{
${ }^{10}$ Of the articles cited in this paragraph, only Campa and Deily use some measure of factor prices and/or output prices.

${ }^{11}$ Lieberman (1987b) also performs a Tobit regression.
} 
and Svensson (1996) and Ó hUallacháin and Reid (1997) use Tobit regression models to address how much investments that go to a certain country/state.

In addition to the above two investment traditions, there is a budding literature departing from the traditional investment literature, but recognising the importance of lumpiness in investments. Cooper et al. (1999) use duration regressions in analysing the time since the previous investment spike. ${ }^{12}$

\section{Model and Data}

\subsection{Determinants of investment}

In this section, we first discuss the variables considered to influence the investments decision according to the factor endowment theory and thereafter variables that can considered as describing the importance of proximity to customers, agglomeration effects and minimization of transaction costs.

According to the Heckscher-Ohlin theory of factor proportions, we should expect a high level of investment in countries where those factors in which the pulp and paper industry is intensive are cheap and/or where those factors are abundant. According to the popular view, investments in general, and investments in capital-intensive industries in particular, are highly sensitive to high wage rates (WAGE) and interest rates $(G B Y)$, respectively. The pulp and paper industry, in particular, can also be adversely affected by high prices of wood $\left(P_{I N D}\right)$, recycled paper $\left(P_{R E T}\right)$ and electric energy $\left(P_{E L}\right)$.

Abundance in factors of production can be measured either directly, i.e., as the supply of these factors or, possibly, through their prices. According to the Heckscher-Ohlin-Samuelson factor price equalization theory, international trade will eliminate factor price differentials, even in the absence of factor mobility. However, transportation costs and other barriers to trade will result in factor prices that are not equal across countries. In addition, in the process towards equilibrium, factor prices will be unequal and investment activities are, in fact, part of the adjustment process. For these reasons, and also because of data availability, we use factor prices as independent variables. ${ }^{13}$

\footnotetext{
${ }^{12}$ See Cooper et al. for further references. See section 4.2 below for their definition of an investment spike.

${ }^{13}$ If the endowment of a factor has increased, a fall in the price of that factor may follow. However, if such an event is predicted, capacity could be expanded to accommodate this increase, so that a fall in factor prices is never observed. This might, for example, be the case with roundwood supply. Including a direct measure of (changes in) factor availability could therefore
} 
More recent theories stress the importance of proximity to customers, agglomeration effects and minimization of transaction costs. According to the 'new' location theory, demand and supply externalities, such as the possibility to use joint networks of suppliers and distributors, could result in pecuniary externalities favoring agglomeration (Krugman, 1991; Venables, 1996). Similarly, the new growth theory (Romer, 1986; Sala-i-Martin, 1990) argues that knowledge spillovers result in positive externalities for competing firms. These theories give additional reasons - besides the capital depreciation argument - why an investment is more likely to occur in a country where the existing capital stock is large.

If, according to modern trade theories, agglomeration effects are important, then the installed base of capital in a country should be an important determinant of the investment level. We measure capital as a weighted average of paper and pulp production capacity $(P R O D p)$ and $(P R O D m)$, respectively. Since the capital requirement per ton of pulp produced is about one third of the capital requirement per ton of paper produced, the weight for $P R O D_{m}$ is one third of that for $P R O D_{P}$. Note, however, that this variable may, in fact, also measure the endowment of unobserved factors of production.

A location close to a large population center could reduce transportation costs or facilitate market access. If proximity to customers is important, firms would invest in countries with large populations and large GDP. The increased reliance on recycled paper may reinforce this effect. For this reason, we introduce population size $(P O P U L)$ and GDP growth rate $(D G D P)$ as well as the interaction between these two variables $(D P)$ as explanatory variables. Naturally, a higher GDP growth rate might indicate higher future demand for paper and/or increased supply of recycled paper.

In summary, the factor endowment theory suggests that new production units will be installed in countries where the relevant factors of production are more abundant, or where factor prices are low relative to other countries. The agglomeration effect suggests that capacity will mainly be installed in countries with large existing stocks. If proximity to customers has become more important, new capacity would be located close to population centres. The introduction of new technologies and increased environmental concern have improved the competitiveness of production facilities based on recycled paper. This effect works in the same direction.

be an alternative approach. We have information on the forest inventory as a direct measure of factor endowment. However, since this measure is available only for 1984, we do not use this information in the analysis. 
A higher price of output (measured as price of printed paper, $P_{P R I}$ ) would tend to increase the likelihood of investments in all countries. A high valuation of the US dollar suggests that the competitive pressure from North American firms will be less intense, leading to higher future output prices. However, to the extent that the dollar appreciation creates an increase in the price of the final product, this will be captured by the parameter for the effect of the output price. Therefore, the explanatory variable $U S / E C U$ (the US\$/ECU exchange rate) will measure the extent to which the European industry will react to an appreciation of the dollar, given the output price.

Because of technological progress, the capacity of the optimally-sized new paper machine increases over time (Christensen and Caves, 1997).${ }^{14}$ Ceteris paribus, this will reduce the number of investments over time, which motivates the inclusion of a time trend, TREND.

\subsection{Time-to-build}

An investment decision is, of course, based on contemporary observations and predictions of future evolution in the market. However, between the date of the decision and the date when the investment is completed (or when the costs of the investment are incurred) a certain time elapses, that is, the "time-to-build". The length of this time-span is relevant to the present study, since we know the date of completion, but are interested in the variables influencing the investment decision.

Mayer (1960) found the weighted (un-weighted) average time to build in the US to be 22 (11) months for industrial plants and Hall (1977) found it to be about two years. More recently, Ghemawat $(1984,1987)$ reports that it takes at least four years to build large chemical industry plants and assumes that it takes two to three years to build a typical industrial plant. Montgomery (1995) notes the paucity of studies of construction times and reports that the value weighted average times-to-build for nonresidential structures in the US 1961-1991 were almost 17 months. ${ }^{15}$

In our sample, we know the year of completion for all investments. In 13 cases,

\footnotetext{
${ }^{14}$ Lieberman $(1987 \mathrm{c})$ reports that the average size of new chemical plants has grown at an annual rate of 8 percent.

${ }^{15}$ The installation rates peaked 6 and 12 months after the projets were started for the average of all projects, 15 and 18 months after the start of projects costing over $\$ 10$ million, and 1 month after the start of projects worth less than $\$ 250,000$. This suggests that the average construction time of large projects exceeds 17 months.
} 
Table 4.1: Frequencies of time-to-build in years. (If the project was initiated in, e.g., 1990 and completed in 1992, the construction time is assumed to be two years. In some instances, the project is, e.g., reported to have been completed in $1992 / 93$. If that project was initiated in 1990, the construction time is calculated to be 2,5 years.)

\begin{tabular}{lllllll}
\hline \hline & \multicolumn{1}{c}{ Years } \\
\hline & 1 & 2 & 2.5 & 3 & 3.5 & 9 \\
Construction start-completion & 2 & 8 & 1 & 2 & & \\
Announcement-completion & & 5 & & 3 & 1 & 2 \\
\hline
\end{tabular}

we know the year when construction began and in 11 (mostly overlapping) cases, we know the year when the new investment was announced. The corresponding times-to-build are shown in Table 4.1. The average time between the start of the construction and its completion is 2 years and the average time between announcement and completion is 3.7 years, or 2.5 years if the two nine-yearprojects are excluded.

\subsection{Data and variables}

In the empirical studies of the chemical industry, "investments" have typically been defined as events having increased plant capacity by more than 5 percent. Cooper et al. (1999) define "investment spikes" as years when the gross investment rate exceeds 20 percent. In the present study, an "investment" is defined as the installation of a new processing unit, i.e., a new paper machine or a new pulp line. An "investment" is considered to have occurred if there is a report of a firm installing a new paper or board machine, if a "new pulp line" with a capacity of at least 50000 tons per year is reported, or if a "pulp expansion" of at least 100000 tons is reported. These investment announcements were collected from European Paper Data Base and Pulp and Paper International: International Fact and Price Book, two statistical yearbooks of the industry. Early announcements that were later cancelled have been eliminated to the extent possible. Conversely, although the yearbooks appear to be fairly comprehensive, there may have been investments that were not reported. The investment is reported the year it was completed.

The annual production of roundwood, pulp and paper and the annual price 
of roundwood in each country are taken from FAO's forestry database; prices are calculated on basis of export values and volumes. The price of electricity (for the industry) is from Electricity Information, IEA/OECD; wages are from Wages and Total Labor Costs for Workers, Swedish Employers' Confederation (Total labor costs for workers in the pulp and paper industry). Missing values are calculated from labor costs in manufacturing. ${ }^{16}$ Interest rates (average longterm government bond yields), exchange rates, GDP (growth), (changes in) price level and population are from the International Statistical Yearbook/OECD/Main economic indicators. The total inventory of forest is from the Statistical Yearbook of Forestry. All prices are expressed in 1990 US\$.

\subsection{Summary}

Descriptive statistics - with explanations - for the variables used in the empirical model are provided in Table 4.2.

\subsection{Model specification}

Let $I_{i t}$ be the number of investments for country $i$ in time-period $t$. We assume the mean number of investments to be log-linear in the unknown parameters, i.e.

$$
E\left(I_{i t} \mid \mathbf{z}_{i t-2}, \alpha_{i}\right)=\exp \left(\alpha_{i}+\mathbf{z}_{i t-2}^{\prime} \boldsymbol{\beta}\right)=\lambda_{i t}^{*} \nu_{i}=\lambda_{i t}, t=1, \ldots, T_{i}
$$

where $\lambda_{i t}^{*}=\exp \left(\mathbf{z}_{i t-2}^{\prime} \boldsymbol{\beta}\right), \nu_{i}=\exp \left(\alpha_{i}\right), \mathbf{z}_{i t-2}$ is the $k \times 1$ vector of the explanatory variables, $\boldsymbol{\beta}$ is the corresponding parameter vector to be estimated and $\alpha_{i}$ is a country-specific effect. ${ }^{17}$ Based on the evidence in Section 4.2 - where we found the modulus and the mean time between the construction/announcement and completion to be approximately two years - the explanatory variables are lagged two years. To enhance the presentation below, let $\mathbf{x}_{i t}=\mathbf{z}_{i t-2}$ and then $\lambda_{i t}^{*}=$ $\exp \left(\mathbf{x}_{i t}^{\prime} \boldsymbol{\beta}\right)$. Since the distribution of construction/announcement to completion times is highly skewed to the right, the analysis is also performed with explanatory variables lagged three years, i.e. $\mathbf{x}_{i t}=\mathbf{z}_{i t-3}$. The results from this analysis are presented in Appendix 2.

\footnotetext{
${ }^{16}$ All values for 1995 are extrapolated from the 1994 values, using changes in wages in the manufacturing sector between these two years. There are five additional missing values for Portugal and Spain, respectively, and one for Denmark, The Netherlands and Switzerland, respectively.

${ }^{17}$ We have an unbalanced panel. For Sweden and Belgium $T_{i}=9$ and for Norway $T_{i}=6$. For all other countries, $T_{i}=10$. In calender time, $t=1$ is 1986 .
} 
Table 4.2: Summary statistics for the case where explanatory variables are lagged two periods. The number of observations for each country is $T=10$ except for Sweden, Norway and Belgium where $T=9,6$ and 9 , respectively. This gives a total of 144 observations.

\begin{tabular}{llrr}
\hline \multicolumn{1}{c}{ Variable } & \multicolumn{1}{c}{ Description } & Mean & Std.dev \\
\hline$I$ & Number of investments in paper and pulp mills & 1.4097 & 1.9626 \\
$W A G E$ & Real hourly wage rate (US $\$ /$ hour) & 16.8050 & 5.1721 \\
$G B Y$ & Government bond yield & 9.3985 & 2.6896 \\
$P_{I N D}$ & Real price of roundwood (US\$/m3) & 0.0776 & 0.0640 \\
$P_{P R I}$ & Real price of printed paper $(\mathrm{US} \$ /$ ton) & 1.0532 & 0.2859 \\
$P_{E L}$ & Real price of electricity (US $\$ / \mathrm{kWh})$ & 0.0686 & 0.0204 \\
$P_{R E T}$ & Real price of recycled paper $(100 \mathrm{US} \$ /$ ton) & 1.4845 & 0.8880 \\
$U S / E C U$ & & 1.1870 & 0.0939 \\
$P O P U L$ & Population $(100$ million) & 0.2507 & 0.2518 \\
$D G D P$ & Real GDP growth $(\%)$ & 2.9316 & 3.9335 \\
$U S / E C U$ & & 1.1870 & 0.0939 \\
$D P$ & DGDP.POPUL & 0.7856 & 1.2868 \\
$P R O D_{p}$ & Production of paper $\left(10^{6}\right.$ tons) & 4.2257 & 3.7456 \\
$P R O D_{M}$ & Production of pulp $\left(10^{6}\right.$ tons) & 2.1233 & 2.9679 \\
$P R O D$ & PROD $_{p}+\frac{1}{3} P R O D_{m}$ & 4.9335 & 4.4195 \\
\hline
\end{tabular}




\section{Estimation and Results}

Concerning the estimation technique, there are two options in handling the countryspecific effects: either as fixed effects or as random effects.

Estimators under the random effect specification are more efficient than estimators under the fixed effect approach. In the random-effect approach, an assumption of the distribution of the country specific effect is needed and the explanatory variables and the country-specific effect need to be independent, in order to remove the effect of the unobservables. ${ }^{18}$ In this study, however, assuming the explanatory variables and country-specific effects to be independent does not seem appropriate. In sub-section 5.1, however, we present estimation results from a negative binomial model.

The fixed-effect approach does not suffer from these two possible problems of the random-effect specification. Under the fixed effects specification, there are two estimators that are consistent under different weak conditions on the explanatory variables; the Poisson conditional maximum likelihood estimator (CMLE) (cf. Hausman, Hall and Griliches, 1984) and the generalized method of moment (GMM) estimator. ${ }^{19}$ Under the assumption of strict exogeneity ${ }^{20}$ of the explanatory variables, the Poisson CMLE (conditioning on $I_{i}=\sum_{t=1}^{T_{i}} I_{i t}$ ) will be a consistent estimator of $\boldsymbol{\beta} .^{21}$ The assumption of strictly exogenous explanatory variables is likely to be true for macroeconomic variables, but the installed base of capital $(P R O D)$ can simply not be strictly exogenous and input and output prices may not be strictly exogenous. The installed base of capital is a direct function of previous investments and investments might change future prices. The GMM estimator is also consistent if the explanatory variables are not strictly exogenous.

\subsection{Results and specification tests}

In Table 5.1, the results for a Poisson model without country-specific effects are presented. We can see that the parameters for PROD, DP and $U S / E C U$ are

\footnotetext{
${ }^{18}$ The distribution can, however, be estimated semi-parametrically, still there are other problems with this approach (see e.g., Titterington et al. 1987).

${ }^{19}$ Nat urally, there are other possible estimators under different distributional assumptions, see, e.g., Hausman et al. (1984). Here, we present estimators under conditional Poisson distribution as well as the corresponding canonical link function for the mean.

${ }^{20}$ For a definition of strict exogenity see, for instance, Gourieroux and Montfort (1995, ch. 1).

${ }^{21}$ It is easily shown, however, that the Poisson maximum likelihood estimator (MLE) with dummy variables will give the same estimates as the Poisson CMLE (see Blundell, Griffith and Windmeijer, 1999).
} 
positive and significant. ${ }^{22}$ The TREND, WAGE and DGDP parameters are negative and significant, and the parameter for $P_{I N D}$ is negative and marginally significant. Hence, the price variables that seem important are the wage rate and $U S / E C U$ exchange rate and, perhaps, the price for material.

We have mild overdispersion - the overdispersion test statistics $(D L)$ of Dean and Lawless (1989) are just significant. The $D L$ has an asymptotically standard normal distribution and the statistics is $D L=2.22$. The serial correlation of the standardized residual is $\hat{\rho}=0.16$. It is of interest to consider the role of $P R O D$ in this model. Excluding this variable changes the results drastically - the results from this exercise are shown in columns 4 and 5 of Table 5.1. It appears that the fit is much worse in the model without $P R O D$ and that we have severe serial correlation and overdispersion. The inference also differs, especially for the $W A G E$ parameter, which changes signs and is now almost significantly positive. We now also have a significant and positive effect of the POPUL. Studying the results when the explanatory variables are lagged three years, given in Table 6.1 in Appendix 2, it appears that the fit of this model is not as good as for the model with a lag length of two years. There are, however, no changes in inference when using this data.

In order to reduce the (small) overdispersion, we first assume $\alpha_{i}$ to be random and integrate it out to obtain the unconditional distribution. The most common approach is to assume that $\nu_{i}=\exp \left(\alpha_{i}\right)$ is gamma distributed with parameters $(\delta, \delta)$. This approach yields the negative binomial (negbin) distribution. The results from the negbin MLE are given in columns 2 and 3 in Table 5.2. We can note that $\alpha$, the parameter indicating overdispersion, is, as expected, not significant and that there is still serial correlation. Furthermore, there are no changes in the inferences from the Poisson MLE.

The consistency of the negbin MLE is based on the assumption of the individual effect being independent of the included explanatory variables; a highly restrictive assumption which can be tested using a Hausman test $(H T)$. This test is against the Poisson CMLE and it is asymptotically $\chi^{2}(k)$ distributed. As can be seen from Table 5.2, we can reject - at a level lower than 12.5 percent - the independence assumption. The parameter estimates from the Poisson CMLE are given in columns 4 and 5 in Table 5.2. First, we can note that no overdispersion, nor any serial correlation is present, since $D L=1.70$ and $\hat{\rho}=-0.01$. A likelihood ratio $(L R)$ test of the fixed effect Poisson model against the standard model is $L R=32.44$. With 14 degrees of freedom, the fixed effect model is clearly

\footnotetext{
${ }^{22}$ At the (at least) 5 percent level.
} 
Table 5.1: Poisson ML (no fixed effects). The t-statistic for the Poisson ML is based on the robust quasi-likelihood covariance matrix. $D L$ is the Dean and Lawless (1989) test for overdispersion which, under the null of no overdispersion, is asymptotically $\mathrm{N}(0,1)$. The $R_{D E V}^{2}$ is the deviance-based goodness of fit measure suggested by Cameron and Wimdmeijer (1996) and $\widehat{\rho}$ is the correlation in the standardized residual.

\begin{tabular}{lrrrr}
\hline \hline \multicolumn{1}{c}{ Variable } & \multicolumn{1}{c}{ Est. } & Est./s.e. & \multicolumn{1}{c}{ Est. } & Est./s.e. \\
\hline$a$ & -2.4030 & -2.066 & -1.9862 & -1.450 \\
$W A G E$ & -0.0909 & -2.362 & 0.0338 & 1.165 \\
$G B Y$ & 0.0650 & 1.420 & 0.1123 & 2.607 \\
$P_{P R I}$ & -0.3852 & -0.916 & -0.9490 & -1.921 \\
$P_{I N D}$ & -1.2633 & -1.550 & -3.0369 & -3.110 \\
$P_{E L}$ & -2.9167 & -0.527 & -1.2326 & -0.229 \\
$P_{R E T}$ & 0.0982 & 1.527 & 0.1624 & 2.197 \\
$U S / E C U$ & 4.2089 & 2.679 & 2.4290 & 1.429 \\
$P O P U L$ & 0.3676 & 0.607 & 2.4700 & 5.791 \\
$D G D P$ & -0.0876 & -3.793 & -0.0561 & -1.303 \\
$D P$ & 0.1721 & 3.522 & 0.1163 & 1.664 \\
$P R O D$ & 0.1808 & 5.257 & & \\
$T R E N D$ & -0.2913 & -5.357 & -0.2724 & -4.244 \\
$D L$ & 2.2218 & 4.0132 \\
$R_{D E V}^{2}$ & 0.5119 & 0.3908 \\
$\hat{\rho}$ & 0.1625 & 0.2590 \\
loglikelihood & -189.0920 & \multicolumn{2}{c}{-209.7395} \\
\hline
\end{tabular}


preferable to the standard Poisson model. Hence, the fix-effect estimator gives a reasonable explanation to the data.

There are five main results: (i) The parameter estimate for wages is oncemore significant and larger than for the Poisson and negbin ML estimators.; (ii) the parameter estimates for $P_{P R I}$ have changed signs and are positive, as expected; (iii) the parameter estimate for the price of electricity is positive and almost significant; (iv) the parameter for $D G D P$ is now significant and negative; and (v) the effect of the installed base of capital $(P R O D)$ is higher but less significant than when using the negbin and the Poisson MLE.

The estimation results from the negbin MLE and the Poisson CMLE when the explanatory variables are lagged three years are given in Table 6.2 in Appendix 2. We can note that almost the same results are found for this data. The fit of the model is worse than for a lag length of two years and there is an indication of overdispersion. The serial correlation seems to have been removed, however, since $\widehat{\rho}=0.05$. The main differences in inference are that: (i) The parameter for $P_{P R I}$ is significant positive; and (ii) the parameter for $U S / E C U, D G D P, D P, P R O D$ and TREND are all insignificant.

The parameter estimates in the Poisson CMLE might be biased because $P R O D$ and some of the prices, e.g., $P_{I N}, P_{P R I}$ and $P_{R E T}$, might not be strictly exogenous. The quasi differencing approach in Chamberlain (1992) can be used to remove the fixed effect and then the parameters can be consistently estimated using a generalized method of moment (GMM) estimator. (For a detailed exposition concerning the GMM estimation, see Appendix 1).

In the estimation, we treat $\mathbf{x}^{p}=\left(P R O D P_{I N}, P_{P R I} P_{R E T}\right)^{\prime}$ as predetermined.. Seven lags for the predetermined variables together with current observations for the remaining eight exogenous variables are used as instruments in the estimation, which produces 36 moment restrictions for estimating the $k=12$ parameters. $^{23}$ We present results for two estimators; the efficient two-step estimator ( $\widehat{\boldsymbol{\beta}}$, GMM 2$)$ and the first-step estimator $(\widetilde{\boldsymbol{\beta}}, \mathrm{GMM} 1)$. The reason for this is that the standard errors from the optimal second-step estimator $\widehat{\boldsymbol{\beta}}$ might be too small, thereby leading to inflated $t$-ratio's (see, e.g., Ogaki, 1993). The minimum, $q(\widehat{\boldsymbol{\beta}})$, for the efficient GMM 2 estimator is the Sargan general misspecification test (Sargan, 1958). $q(\widehat{\boldsymbol{\beta}})$ is asymptotically chi square distributed with 24 degrees of freedom. The resulting estimates for the GMM estimation and the Poisson MLE together with the Sargan test and the Arellano and Bond (1991) test for first-order serial

\footnotetext{
${ }^{23}$ An increase in $l$ will lead to increased asymptotic efficiency, but may lead to increased bias in finite samples (Davidson and MacKinnon, 1993, Ch. 17.3).
} 
Table 5.2: Negative binomial MLE and Poisson CMLE. DL is the Dean and Lawless (1989) test for overdispersion which, under the null of no overdispersion, is asymptotically $\mathrm{N}(0,1)$. The $R_{D E V}^{2}$ is the deviance-based goodness of fit measure suggested by Cameron and Wimdmeijer (1996) and $\hat{\rho}$ is the correlation in the standardized residual.

\begin{tabular}{|c|c|c|c|c|}
\hline \multirow{2}{*}{$\begin{array}{c}\text { Estimator } \\
\text { Variable }\end{array}$} & \multicolumn{2}{|c|}{ negbin. MLE } & \multicolumn{2}{|c|}{ Poisson CMLE } \\
\hline & Est. & Est./s.e. & Est. & Est./s.e. \\
\hline$a$ & -2.2008 & -1.733 & & \\
\hline$W A G E$ & -0.0909 & -2.602 & -0.2306 & -3.207 \\
\hline$G B Y$ & 0.0642 & 1.375 & 0.0676 & 0.941 \\
\hline$P_{P R I}$ & -0.3987 & -0.944 & 1.0559 & 1.188 \\
\hline$P_{I N D}$ & -1.3022 & -0.915 & -3.3287 & -1.513 \\
\hline$P_{E L}$ & -2.5881 & -0.466 & 28.2702 & 1.658 \\
\hline$P_{R E T}$ & 0.0895 & 0.839 & 0.1478 & 1.284 \\
\hline$U S / E C U$ & 4.0572 & 2.439 & 3.5503 & 1.836 \\
\hline$P O P U L$ & 0.3095 & 0.536 & -0.4882 & -0.148 \\
\hline$D G D P$ & -0.0895 & -2.681 & -0.0968 & -2.728 \\
\hline$D P$ & 0.1804 & 2.255 & 0.1867 & 2.383 \\
\hline$P R O D$ & 0.1822 & 5.793 & 0.4686 & 2.348 \\
\hline$T R E N D$ & -0.2913 & -5.428 & -0.2308 & -2.469 \\
\hline$\alpha$ & 0.1216 & 1.218 & & \\
\hline$D L$ & \multicolumn{4}{|c|}{1.7011} \\
\hline$H T$ & \multicolumn{4}{|c|}{17.6401} \\
\hline$R_{D E V}^{2}$ & \multicolumn{2}{|c|}{0.4718} & \multicolumn{2}{|c|}{0.6069} \\
\hline$\widehat{\rho}$ & \multicolumn{2}{|c|}{0.1671} & \multicolumn{2}{|c|}{-0.0085} \\
\hline Loglikelihood & \multicolumn{2}{|c|}{-188.0157} & \multicolumn{2}{|c|}{-172.8736} \\
\hline
\end{tabular}


correlation are presented in Table 5.3.

Since $q(\widehat{\boldsymbol{\beta}})=13.35$, we cannot reject the model. Using a Monte Carol study, Blundell et al. (1999) observe, however, that if $\left\{\mathbf{x}_{i t}\right\}$ are highly persistent, the quasi-differenced GMM estimator can be severely biased in small samples and that the Sargan test is not very powerful in this case. Our data on explanatory variables are relatively persistent, hence the nominal level of the Sargan test might not be correct. We can also note that no serial correlation seems to be present, since the Arellano and Bond (1991) test for first-order serial correlation are reasonably low.

From Table 5.3, we first note that all variables have the expected sign, except the positive effect for the $G B Y$ and $P_{R E T}$ and the - marginally significant - DGDP, which is negative. The effect of $P_{P R I}$ is significant and of the same magnitude as for the Poisson CMLE. The parameter estimates for $P_{I N D}$ are now negative and almost significant for the GMM 2 estimator. $P_{R E T}$ is positive and significant for the GMM 2 estimator. The parameter for $P_{E L}$ is now, as expected, negative but not significant. There is a large positive estimated effect of the same magnitude as for the other estimators for the $U S D / E C U$ variable. The previously found negative TREND parameter is not significant with this estimator. We can also note that the effect of the installed base of capital is larger than for the Poisson CMLE regression.

The GMM approach can also be used to test whether our assumed variables can be treated as strictly exogenous. Instead of using lags for the four variables, the leads up to seven time periods together with current observations on the remaining eight variables (see Appendix 1 for more details) are used as instruments in the GMM estimation. The resulting Sargan test is again $\chi^{2}(24)$ and since $q(\widehat{\boldsymbol{\beta}})=17.28$, we cannot reject exogeneity at any reasonable level of significance. This confirms the results found in Blundell et al. (1999), in that the Sargan test is not very powerful, since the installed base of capital cannot be strictly exogenous. It is worth nothing, though, that the Sargan test statistic is larger when we treat the variables as strictly exogenous, rather than predetermined. To some extent, this justifies treating the variables in $\mathbf{x}^{p}$ as predetermined. Using the same argument, the Sargan test is an indication that the model based on two years of lagged explanatory variables should be preferred to the model with a lag length of three years, since for lag length three, $q(\widehat{\boldsymbol{\beta}})=15.79$ (see Table 6.3 )

In Table 6.3, the results from the GMM estimation where the explanatory variables have a three-year lag are presented. Certain quite large differences are found in the results, compared to the results with a lag length of two years. The most notable difference is the insignificant (but negative) effect of wages and the 
Table 5.3: GMM estimates. ( $m_{1}$ is the Arellano and Bond (1991) test for firstorder serial correlation. It is asymptotically $\mathrm{N}(0,1)$ under the null hypothesis.)

\begin{tabular}{lrrrr}
\hline \hline \multicolumn{1}{c}{ Estimator } & \multicolumn{2}{c}{ GMM 1, $\boldsymbol{\beta}$} & \multicolumn{2}{c}{ GMM 2, $\widehat{\boldsymbol{\beta}}$} \\
\multicolumn{1}{c}{ Variable } & \multicolumn{1}{c}{ Est. } & Est./s.e. & \multicolumn{1}{c}{ Est. } & Est./s.e \\
\hline$W A G E$ & -0.377 & -0.994 & -0.334 & -4.041 \\
$G B Y$ & 0.259 & 1.938 & 0.259 & 3.932 \\
$P_{P R I}$ & 3.443 & 1.008 & 2.697 & 2.799 \\
$P_{I N D}$ & -1.503 & -0.445 & -2.482 & -1.690 \\
$P_{E L}$ & -9.855 & -0.176 & -15.414 & -0.872 \\
$P_{R E T}$ & 0.552 & 0.812 & 0.595 & 2.387 \\
$U S / E C U$ & 5.148 & 1.498 & 5.202 & 4.188 \\
$P O P U L$ & -1.790 & -0.347 & -0.987 & -0.444 \\
$D G D P$ & -0.031 & -0.530 & -0.046 & -1.842 \\
$D P$ & 0.021 & 0.148 & 0.072 & 1.525 \\
$P R O D$ & 0.380 & 0.592 & 0.545 & 2.473 \\
TREND & 0.010 & 0.017 & -0.109 & -0.802 \\
Sargan, $q(\widehat{\boldsymbol{\beta}})$ & & & 13.3489 \\
$p-$ value & & & 0.9600 \\
$m_{1}$ & & & -1.1944 \\
\hline
\end{tabular}

significant positive effect of $P_{I N D}, D G D P$ and $T R E N D$. The results found for the GMM estimator with a lag length of three years is most probably due to the fact that the instruments get weaker with the increasing lag length of the explanatory variables. Based on the Sargan test and the parameter estimates from all the presented models, we believe the model with a lag length of two years to be preferable and the following discussion will be based on the result from using this data only.

\subsection{Interpretation of the results}

The reported estimation methods have both advantages and disadvantages. The advantage of the GMM estimator is that it is also consistent when strict exogeneity of the explanatory variables does not hold, while the disadvantage is that it may be biased in small samples. From the results of the conventional Poisson 
ML estimation, we can see (see Tables 5.1 and 6.1, regarding lag lengths of two and three years, respectively) that the $P R O D$ measure is essential in reducing heterogeneity between the countries. It is, however, evident that the fixed effect estimator reduces the correlation in the residuals and removes the small amount of overdispersion present in the model. Furthermore, an $L R$ test revealed the fixed-effect model to be preferable to the standard Poisson model. The negative binomial model did not reduce the correlation and hence, we believe this model to be inferior, since the Poisson ML is robust to miss-specifications, while the negbin is not.

The CMLE is likely to be biased, since unobserved heterogeneity is present and correlated with included regressors. Hence, the GMM estimator is preferred over the others, despite its problem in small samples. It is, however, interesting to compare the estimates from these different estimators. In Table 5.4, the results are summarized. Positive parameter estimates are indicated by + and negative estimates by -. The significance at the five percent level is indicated by *

The main results shown in the table are that: (i) The PROD variable also influences investments when fixed country effects are accounted for; (ii) the wage rate, $W A G E$, has a negative effect on the investment level; (iii) $U S / E C U$ has a positive effect on the investment; (iv) $P_{P R I}$ and $P_{R E T}$ may have positive effects on investments; (v) $P_{I N D}$ may have a negative effect on investment; (vi) there appears to be no effect from $P O P U L$ or $D G D P$ on investments.

It should be observed that the standard Poisson ML estimator is consistent in the presence of unobserved heterogeneity, if the unobserved heterogeneity is uncorrelated with the included explanatory variables. Consider the estimates from the Poisson MLE in Table 5.1 and the fix-effect estimators given in Tables 5.2 and 5.3. We can see that the estimated parameters for the Poisson MLE are generally smaller (in absolute value) for the country-specific variables, $W A G E$ and PROD. For the common variables, like $U S / E C U$ and $T R E N D$, there are no large differences between the estimators. This indicates that the unobserved country-specific term is correlated with $W A G E$ and $P R O D$ and that the correlations are positive and negative, respectively. Hence, countries with a high unobserved propensity to invest also have high $W A G E S$ and low PROD. Hence, this correlation reduces the effect of wages and $P R O D$ on the investment propensity by using the Poisson MLE.

Concerning the economic significance of the estimated effects, the parameters can be interpreted as semi elasticities in the log-linear mean specification, i.e., if the $k: t h$ explanatory variable is increased by one unit, the expected number of 
Table 5.4: Summary of Poisson ML, CMLE, first step GMM and second step GMM estimates.

\begin{tabular}{lllll}
\hline \hline & \multicolumn{3}{c}{ Poisson } & \multicolumn{2}{c}{ GMM } \\
& MLE & CMLE & 1 & 2 \\
\hline$P R O D$ & $+^{*}$ & $+^{*}$ & + & $+^{*}$ \\
$P_{P R I}$ & - & + & + & $+^{*}$ \\
$P_{I N D}$ & - & - & - & - \\
$P_{R E T}$ & + & + & + & $+^{*}$ \\
$P_{E L}$ & - & + & - & - \\
$W A G E$ & $-*$ & $-*$ & - & $-^{*}$ \\
GBY & + & + & + & $+^{*}$ \\
$P O P U L$ & + & - & - & - \\
$D G D P$ & $-*$ & $-^{*}$ & - & - \\
$D P$ & $+^{*}$ & $+^{*}$ & + & + \\
US/ECU & $+^{*}$ & + & + & $+^{*}$ \\
TREND & $-^{*}$ & $-*$ & \multicolumn{2}{c}{+} \\
\hline
\end{tabular}

investments increases/decreases proportionally with $\beta_{k}$. For example, if $P R O D$ increases by 1 unit ( 1 million ton), the number of investments will increase by $18-55$ percent according to the different estimates. Calculated as the effect of a ten-percent increase of capacity from the average capacity of 4.9 million tons, the number of investments would increase by $9-27$ percent. A ten-percent decrease in $W A G E S$ would induce a $15-56$ percent increase in investments. A ten-percent increase in $U S / E C U$ exchange rate would increase investments by $42-60$ percent. Using only the estimates from the GMM 2 estimator, we find that a ten-percent increase in the price of printed paper would lead to an increase of almost 30 percent in investments. For the other significant variables a ten-percent increase leads to only minor changes in investments and hence, are of no economic significance. For example, a ten-percent decrease in the roundwood price would increase the investment by around two percent.

These results can, most readily, be compared to those on the location of international investments. Bartik (1985), e.g., finds that an increase in the industrial production in a US state will increase the likelihood of an inward investment almost proportionately and that a ten-percent increase of the wage level will reduce the likelihood of investments by around nine percent. Coughlin et al. (1991) report that a ten-percent increase of the wages will reduce the likelihood of investments by around 44 percent and that ten percent higher GDP per capita increases investments by 60-70 percent. Braunerhjelm and Svensson (1996) find 
positive effects of industrial agglomeration and market size, while Friedman et al. (1992) report that the wage level, the tax rate, access to a harbour and average labour productivity are the most important determinants of investments.

\section{Conclusions}

According to our estimates, the factors mainly influencing a firm's decision to invest in pulp lines and paper machines are the wage rate, the installed productive capacity, the price of paper and the $U S / E C U$ exchange rate.

The positive effect of the installed capacity supports the hypothesis of an agglomeration effect. The parameters for GDP growth and population are most often negative and not significant, while the interaction term has a small effect. These variables measure both local market size and supply of waste paper. The lack of (statistical and economic) significance means that no support is given to the hypotheses that proximity to customers or local access to waste paper are of importance for the investment decision.

Note that in contrast to most studies within this tradition, we have included variables measuring factor prices. It is interesting to note that, most often, the interest rate has no significant effect (when there is a significant effect, it is positive) and the price of wood input only has a small effect. Since capital can easily be transferred over borders, this might be expected. In addition, our measure of the capital cost does not include the expected currency depreciation: correcting for this will make the capital cost virtually identical across countries. Although transportation costs for wood input are relatively high, wood is tradeable and imports account for a relatively large fraction of consumption in Finland and Sweden. This is also true for waste paper. In contrast, labour does not easily move across borders.

We have chosen to estimate a model for the total number of investments in each country, i.e., investments in both paper machines and pulp lines. Accordingly, we use only the prices of the final product - paper - and the original inputs roundwood and recycled paper. An alternative approach would have been to estimate separate equations for investments of the two types. Then, the price of pulp would be the input price in the paper industry and the output price in the pulp industry. However, we view the industry as an integrated industry producing paper from wood, which is, to a large extent, true both at the firm and the plant level. 


\section{References}

Arellano, M., and S. Bond. "Some test of specification for panel data: Monte Carlo evidence and an application to employment equations". Review of Economic studies 58, 277-298, 1991.

Bartik, T.J. "Business Location Decision in the United States: Estimates of the Effects of Unionization, Taxes, and Other Characteristics of States", Journal of Business and Economic Statistics, 3, 14-22, 1985.

Blundel,R., Griffith, R. and F Windmeijer. "Individual effects and dynamics in count data models", The institute for fiscal studies, working paper series no. W99/3, 1999.

Braunerhjelm, Pontus and Roger Svensson "Host country characteristics and agglomeration in foreign direct investment", Applied Economics, 28, 833840, 1996.

Campa, José M. "Multinational investment under uncertainty in the chemical processing industries", Journal of International Business Studies, 25, 557578, 1994.

Cameron, A.C. and F. Windmeijer " $R$ - Squared Measures for Count Data Regression Models with Applications to Health-Care Utilization". Journal of Business and Economic Statistics, 14, 209- 220, 1996.

Chirinko, Robert S. "Business Fixed Investment Spending: Modeling Strategies, Empirical Results, and Policy Implications", Journal of Economic Literature, 31, 1875-1911, 1993.

Christensen, Laurits R. and Richard E. Caves "Cheap Talk and Investment Rivalry in the Pulp and Paper Industry", The Journal of Industrial Economics, 45, 47-73, 1997.

Cooper, Russels, John Haltiwanger and Laura Power, "Machine Replacement and the Business Cycle: Lumps and Bumps", American Economic Review, 89, 921-946, 1999.

Coughlin, C.C., J.V. Terza and V. Arromdee, "State characteristics and the location of foreign direct investments within the United States, Review of Economics and Statistics, 73, 675-683, 1991. 
Davidson and MacKinnon, Estimation and Inference in Econometrics. Oxford University Press Inc., New York, 1993.

Dean C. and F. Lawless "Test for Detecting Overdispersion in Poisson Regression Models", Journal of the American Statistical Association, 84, 467- 472, 1989.

Deily, Mary E. "Exit Strategies and Plant-Closing Decisions: The Case of Steel", Rand Journal of Economics, 22, 250-263, 1991.

Doms, Mark and Timothy Dunne, "Capital Adjustment Patterns in Manufacturing Plants", U.S. Bureau of the Census, Center for Economic Studies Discussion Paper No. 94/11, August 1994.

Friedman, J., D.A. Gerlowski and J. Silberman, "What attracts foreign multinational corporations? Evidence from branch plant location in the United States, Journal of Regional Science, 32, 403-418, 1992.

Ghemawat, Pankaj "Capacity expansion in the titanium dioxide industry", Journal of Industrial Economics, 33, 145-163, 1984.

Ghemawat, Pankaj "Investment in lumpy capacity", Journal of Economic Behavior and Organization, 8, 265-277, 1987.

Gourieroux, C. and A. Montfort, Statistics and econometric Models, Cambridge University Press New York, 1995

Hall, R.E. "Investment, interest rates, and the effects of stabilization policies", Brookings Papers on Economic Activity, 6, 61-100, 1977.

Hausman, J., B.H. Hall and Z. Griliches, "Econometric models for count Data with an application to the patents-R and D relationship", Econometrica , 52 909-938, 1984.

Head, Keith, John Ries and Deborah Swenson, "Agglomeration benefits and location choice: Evidence from Japanese manufacturing investments in the United States", Journal of International Economics, 38, 223-247, 1995.

Hunter, Helen, "Innovation, competition, and locational changes in the pulp and paper industry, 1880-1950", Land Economics, 31, 314-327, 1955. 
Kovenock, Dan and Gordon M. Philips "Capital structure and product market behavior: An examination of plant exit and investment decisions", Working paper No. 89, Center for Economic Studies, University of Munich, 1995.

Krugman, Paul "Increasing returns and economic geography", Journal of Political Economy, 99, 483-500, 1991.

Lieberman, Marvin B. "Excess capacity as a barrier to entry: An empirical appraisal", The Journal of Industrial Economics, 35, 607-627, 1987a.

Lieberman, Marvin B. "Postentry investment and market structure in the chemical processing industries", Rand Journal of Economics, 18, 533-549, 1987b.

Lieberman, Marvin B. "Market growth, economics of scale, and plant size in the chemical industries", The Journal of Industrial Economics, 36, 175-191, $1987 \mathrm{c}$.

Lieberman, Marvin B. and Richard J. Gilbert "Investment and coordination in oligopolistic industries", Rand Journal of Economics, 18, 17-33, 1987.

Mayer, T. "Plant and equipment lead times", Journal of Business, 33, 127-132, 1960.

Montgomery, Michael R. "Time-to-build completion patterns for nonresidential structures 1961-1991", Economics Letters, 48, 155-163, 1995.

Nilsen, Øivind and Fabricio Schiantarelli, "Zeroes and Lumps in Investment: Empirical Evidence on Irreversibilitites and Non-convexities", mimeo, Boston College, March 1998.

Ogaki , M. "Generalized Method of Moments: Econometric Applications" in G.S. Maddala, C.R Rao and H.D Vinod (Eds.) "Handbook of Statistics Vol 11", Elsevier Science Publisher B.V, 1993

Ó hUuallacháin, Breandán and Neil Reid, "Acquisition versus greenfield investment: The location and growth of Japanese Manufacturers in the United States, Regional Studies, 31, 403-416, 1997.

Paraskevopoulos, D. and C.N. Pitelis "An econometric analysis of the determination of capacity expansion investment in the West European chemical industry", Managerial and Decision Economics, 16, 619-632, 1995. 
Romer, P. "Increasing returns to scale and long-run growth", Journal of Political Economy, 94, 1002-1037, 1986.

Sargan, J.D. "The estimation of economic relationships using instrumental variables", Econometrica, 26, 393-415, 1958.

Sala-i-Martin, X, "Lecture notes on economic Growth, NBER Working Paper No. 3563 and 3564, Cambridge, MA.

Tittirington, D.M., A.F.M. Smith, and U.E. Makov, Finite Mixture Distributions. Chichester: John Wiley \& Sons, 1987.

Venables, Anthony J. "Equilibrium locations of vertically linked industries", International Economic Review, 37, 341-59, 1996.

Zavatta, Roberto "The pulp and paper industry", in H.W. de Jong (Ed.) "The structure of European Industry", 3rd edition, Kluwer Academic Publishers, Dordrecht, 1993. 


\section{Appendix 1}

The Chamberlain (1992) transformation to remove the fixed effect is

$$
\varepsilon_{i t}=I_{i t-1}-I_{i t} \frac{\lambda_{i t-1}^{*}}{\lambda_{i t}^{*}}
$$

Let $\mathbf{x}_{i t}=\left(\mathbf{x}_{i t}^{p \prime}, \mathbf{x}_{i t}^{e \prime}\right)^{\prime}$, where $\mathbf{x}_{i t}^{p}$ is the $k_{p} \times 1$ vector of predetermined variables and $\mathbf{x}_{i t}^{e}$ is the $k_{e} \times 1$ vector of strictly exogenous variables, hence $k=k_{p}+k_{e}$.

We assume that $\mathbf{x}_{i t}^{p}=\left(P R O D_{i t}, P_{I N, i t}, P_{P R I, i t} \text { and } P_{R E T, i t}\right)^{\prime}$, hence $k_{p}=4$. We have that $E\left(\varepsilon_{i t} \mid \mathbf{x}_{i t-j}^{p}\right)=\mathbf{0}, t=2, . ., T_{i}$, where $j=1, \ldots, J$ and where $J$ is chosen to be 7 . For strictly exogenous variables, we use only the following $k_{e}$ moment conditions $E\left(\varepsilon_{i t} \mid \mathbf{x}_{i t}^{p}\right)=\mathbf{0}, t=2, . ., T_{i}$. In all, we have $l=k_{p} J+k_{e}=36$ moment restrictions to estimate the $k=12$ parameters. ${ }^{24}$

The $l \times 1$ vector of instruments are $\mathbf{z}_{i t}=\left(\mathbf{x}_{i t-1}^{p \prime}, \mathbf{x}_{i t}^{e \prime}, \ldots, \mathbf{x}_{i t-J}^{p \prime},\right)^{\prime}$, where $\mathbf{x}_{i t-J}^{p}=$ $\mathbf{0}$, if $J \geq t$. Define the moment restrictions $\mathbf{m}\left(\mathbf{z}_{i t} ; \boldsymbol{\beta}\right)=\mathbf{z}_{i t} \varepsilon_{i t}$, with $E\left(\mathbf{m}\left(\mathbf{z}_{i t} ; \boldsymbol{\beta}\right)\right)=$ 0. The GMM estimator $\widehat{\boldsymbol{\beta}}$ minimizes a quadratic form

$$
\widehat{\boldsymbol{\beta}}=\arg \min _{\beta} \mathbf{m}(\mathbf{z} ; \boldsymbol{\beta})^{\prime} \mathbf{A}_{N} \mathbf{m}(\mathbf{z} ; \boldsymbol{\beta}),
$$

where $\mathbf{m}(\mathbf{z} ; \boldsymbol{\beta})=\sum_{i=1}^{n} \sum_{t=1}^{T_{i}} \mathbf{m}\left(\mathbf{z}_{i t} ; \boldsymbol{\beta}\right)$ is an $(l \times 1)$ vector of empirical moment restrictions. The matrix $\mathbf{A}_{N}$ is an $(l \times l)$ positive definite weighting matrix, such that $\operatorname{plim}_{N \rightarrow \infty} \mathbf{A}_{N}=\mathbf{A}$. The estimator $\widehat{\boldsymbol{\beta}}$ is, under mild regularity assumptions, consistent and normally distributed with the covariance matrix

$$
\operatorname{Cov}(\widehat{\boldsymbol{\beta}})=\left\{\mathbf{D}^{\prime} \mathbf{A D}\right)^{-1}\left\{\mathbf{D}^{\prime} \mathbf{A} \mathbf{\Phi} \mathbf{A D}\right)\left\{\mathbf{D}^{\prime} \mathbf{A D}\right)^{\prime-1},
$$

where $\mathbf{D}$ is the $(l \times p)$ matrix $\partial \mathbf{m}(\mathbf{z} ; \boldsymbol{\beta}) / \partial \boldsymbol{\beta}$. If $\mathbf{A}=\boldsymbol{\Phi}^{-1}=E\left[\mathbf{m}\left(\mathbf{z}_{i t} ; \boldsymbol{\beta}\right) \mathbf{m}\left(\mathbf{z}_{i t} ; \boldsymbol{\beta}\right)^{\prime}\right]^{-1}$, the estimator is asymptotically efficient (in the class of the given moment restrictions) and the asymptotic covariance matrix reduces to $\left(\mathbf{D}^{\prime} \Phi^{-1} \mathbf{D}\right)^{-1} . \hat{\mathbf{\Phi}}$ is estimated by using the identity matrix to obtain an initial $\widetilde{\boldsymbol{\beta}}$ (GMM 1). The consistent Newey and West (1987) estimator is then formed from $\widetilde{\boldsymbol{\beta}}$ and used in a second step to obtain an efficient estimator, $\widehat{\boldsymbol{\beta}}$ (GMM 2). A consistent estimator of the covariance matrix is given by

$$
\operatorname{Cov}(\widehat{\boldsymbol{\beta}})=\left(\hat{\mathbf{D}}^{\prime} \hat{\boldsymbol{\Phi}}^{-1} \hat{\mathbf{D}}\right)^{-1},
$$

\footnotetext{
${ }^{24} \mathrm{An}$ increase in $l$ will lead to increased asymptotic efficiency, but may lead to increased bias in finite samples (Davidson and MacKinnon, 1993, Ch. 17.3).
} 
where $\hat{\mathbf{D}}$ is the $(l \times p)$ matrix $\mathbf{D}$ evaluated at $\widehat{\boldsymbol{\beta}}$. The Newey and West (1987) estimator is

$$
\hat{\boldsymbol{\Phi}}=\widehat{\boldsymbol{\Gamma}}(0)+\sum_{j=1}^{P}\left(1-\frac{j}{P+1}\right)\left(\widehat{\boldsymbol{\Gamma}}(j)+\widehat{\boldsymbol{\Gamma}}(j)^{\prime}\right),
$$

where

$$
\widehat{\boldsymbol{\Gamma}}(j)=\sum_{i=1}^{n} \sum_{t=j}^{T_{i}} \mathbf{z}_{i t-j} \varepsilon_{i t-j}(\widehat{\boldsymbol{\beta}}) \varepsilon_{i t}(\widehat{\boldsymbol{\beta}}) \mathbf{z}_{i t}^{\prime}, j=0, \ldots, P,
$$

and $P$ is the lag truncation parameter, here set to $P=5$. The minimum, $q(\widehat{\boldsymbol{\beta}})$, for the efficient GMM 2 estimator is the Sargan general misspecification test (Sargan, 1958). $q(\widehat{\boldsymbol{\beta}})$ is asymptotically chi square distributed with $k_{p}(J-1)=24$ degrees of freedom.

The test for whether the four predetermined variables can be treated as strictly exogenous is performed, using the $k_{p}(J-1)$ moment conditions $E\left(\varepsilon_{i t} \mid \mathbf{x}_{i t+j}^{p}\right)=$ $\mathbf{0}, t=1, . ., T_{i}-j$, where $j=1, \ldots, J$ and $J=7$. 


\section{Appendix 2}

Table 6.1: Poisson ML (no fixed effects) using the data with a lag length of three years. The t-statistic for the Poisson ML is based on the robust quasi-likelihood covariance matrix. $D L$ is the Dean and Lawless (1989) test for overdispersion which, under the null of no overdispersion, is asymptotically $\mathrm{N}(0,1)$. The $R_{D E V}^{2}$ is the deviance- based goodness of fit measure suggested by Cameron and Wimdmeijer (1996) and $\hat{\rho}$ is the correlation in the standardized residual.

\begin{tabular}{lrrrr}
\hline \hline \multicolumn{1}{c}{ Variable } & \multicolumn{1}{c}{ Est. } & Est./s.e. & \multicolumn{1}{c}{ Est. } & Est./s.e. \\
\hline$a$ & -1.3634 & -1.937 & -1.0733 & -1.328 \\
$W A G E$ & -0.1114 & -3.341 & 0.0204 & 0.642 \\
$G B Y$ & 0.0222 & 0.507 & 0.0503 & 1.122 \\
$P_{P R I}$ & -0.2822 & -0.617 & -0.9592 & -1.999 \\
$P_{I N D}$ & 1.3626 & 0.844 & -0.2024 & -0.124 \\
$P_{E L}$ & -6.7883 & -1.238 & -6.7271 & -1.309 \\
$P_{R E T}$ & 0.1326 & 0.757 & 0.2968 & 1.862 \\
$U S / E C U$ & 3.6788 & 3.640 & 2.1231 & 2.122 \\
$P O P U L$ & 0.4667 & 0.793 & 2.7980 & 6.493 \\
$D G D P$ & -0.0442 & -1.085 & 0.0046 & 0.119 \\
$D P$ & 0.0355 & 0.449 & -0.0606 & -0.706 \\
$P R O D$ & 0.1927 & 6.204 & \multicolumn{2}{c}{-4.879} \\
TREND & -0.2847 & -5.912 & -0.2667 & -4.4369 \\
DL & 3.2392 & 0.3373 \\
$R_{D E V}^{2}$ & 0.4726 & 0.2517 \\
$\rho$ & 0.1459 & -222.2262 \\
loglikelihood & -198.9328 & \multicolumn{3}{c}{} \\
\hline
\end{tabular}


Table 6.2: Negative binomial MLE and Poisson CMLE for a lag length of three years for the explanatory variables. $D L$ is the Dean and Lawless (1989) test for overdispersion which, under the null of no overdispersion, is asymptotically $\mathrm{N}(0,1)$. The $R_{D E V}^{2}$ is the deviance based goodness of fit measure suggested by Cameron and Wimdmeijer (1996) and $\widehat{\rho}$ is the correlation in the standardized residual.

\begin{tabular}{|c|c|c|c|c|}
\hline \multirow{2}{*}{$\begin{array}{c}\text { Estimator } \\
\text { Variable }\end{array}$} & \multicolumn{2}{|c|}{ negbin. ML } & \multicolumn{2}{|c|}{ Poisson CMLE } \\
\hline & Est. & Est./s.e. & Est. & Est./s.e. \\
\hline$a$ & -1.1501 & -1.313 & & \\
\hline$W A G E$ & -0.1175 & -3.121 & -0.2391 & -3.158 \\
\hline$G B Y$ & 0.0159 & 0.356 & 0.0343 & 0.507 \\
\hline$P_{P R I}$ & -0.4062 & -0.911 & 2.5376 & 2.750 \\
\hline$P_{I N D}$ & 1.5936 & 1.258 & 1.3806 & 0.795 \\
\hline$P_{E L}$ & -7.7019 & -1.256 & 11.8437 & 0.904 \\
\hline$P_{R E T}$ & 0.1231 & 0.652 & 0.1551 & 0.556 \\
\hline$U S / E C U$ & 3.8600 & 3.076 & 1.8917 & 1.126 \\
\hline POPUL & 0.4096 & 0.668 & -0.6425 & -0.238 \\
\hline$D G D P$ & -0.0453 & -1.234 & -0.0222 & -0.536 \\
\hline$D P$ & 0.0544 & 0.557 & -0.0436 & -0.477 \\
\hline$P R O D$ & 0.1943 & 5.886 & 0.2803 & 1.452 \\
\hline TREND & -0.2985 & -4.940 & -0.0886 & -0.984 \\
\hline$\alpha$ & 0.2028 & 1.819 & & \\
\hline$D L$ & \multicolumn{4}{|c|}{2.2444} \\
\hline$H T$ & \multicolumn{4}{|c|}{16.3131} \\
\hline$R_{D E V}^{2}$ & \multicolumn{2}{|c|}{0.5235} & \multicolumn{2}{|c|}{0.5836} \\
\hline & \multirow{2}{*}{\multicolumn{2}{|c|}{$\begin{array}{c}0.1550 \\
-196.0328\end{array}$}} & \multirow{2}{*}{\multicolumn{2}{|c|}{$\begin{array}{c}0.0515 \\
-179.8192\end{array}$}} \\
\hline loglikelihood & & & & \\
\hline
\end{tabular}


Table 6.3: GMM estimates for the data with a lag length of three years. ( $m_{1}$ is the Arellano and Bond (1991) test for first-order serial correlation. It is asymptotically $\mathrm{N}(0,1)$ under the null hypothesis.)

\begin{tabular}{lrrrr}
\hline \hline \multicolumn{1}{c}{ Estimator } & \multicolumn{2}{c}{ GMM 1, $\boldsymbol{\beta}$} & \multicolumn{2}{c}{ GMM $2, \widehat{\boldsymbol{\beta}}$} \\
\multicolumn{1}{c}{ Variable } & \multicolumn{1}{c}{ Est. } & Est./s.e. & \multicolumn{1}{c}{ Est. } & Est./s.e. \\
\hline$W A G E$ & -0.082 & -0.385 & -0.063 & -0.683 \\
GBY & 0.096 & 0.414 & 0.042 & 0.606 \\
$P_{P R I}$ & 8.161 & 2.707 & 7.184 & 5.489 \\
$P_{I N D}$ & 3.723 & 1.458 & 3.186 & 2.575 \\
$P_{E L}$ & -29.291 & -0.532 & -29.693 & -1.596 \\
$P_{R E T}$ & -0.292 & -0.286 & -0.115 & -0.451 \\
US $/ E C U$ & -1.394 & -0.358 & -1.306 & -0.925 \\
$P O P U L$ & -8.797 & -1.276 & -6.904 & -3.381 \\
$D G D P$ & 0.239 & 3.013 & 0.185 & 3.792 \\
$D P$ & -0.583 & -3.132 & -0.493 & -4.953 \\
$P R O D$ & -0.026 & -0.038 & 0.134 & 0.505 \\
TREND & 0.439 & 1.225 & 0.314 & 2.226 \\
Sargan, $q(\widehat{\boldsymbol{\beta}})$ & & & \multicolumn{3}{c}{15.7913} \\
$p-$ value & & & \multicolumn{3}{c}{-1.7147} \\
$m_{1}$ & & & \multicolumn{3}{c}{} \\
\hline
\end{tabular}

